\title{
BMJ Open Is outpatient care benefit distribution of government healthcare subsidies equitable in rural ethnic minority areas of China? Results from cross-sectional studies in 2010 and 2013
}

\author{
Mingsheng Chen, ${ }^{1,2}$ Dongfu Qian, ${ }^{1,2}$ Zhanchun Feng, ${ }^{3}$ Lei Si ${ }^{4}$
}

To cite: Chen M, Qian D, Feng Z, et al. Is outpatient care benefit distribution of government healthcare subsidies equitable in rural ethnic minority areas of China? Results from cross-sectional studies in 2010 and 2013. BMJ Open 2018;8:e019564. doi:10.1136/ bmjopen-2017-019564

- Prepublication history for this paper is available online. To view these files, please visit the journal online (http://dx.doi org/10.1136/bmjopen-2017019564).

Received 10 September 2017 Revised 28 December 2017 Accepted 4 January 2018

Check for updates

${ }^{1}$ Department of Public

Administration, School of Health Policy and Management, Nanjing Medical University, Nanjing,

China

${ }^{2}$ Institute of Healthy Jiangsu Construction and Development, Nanjing, China

${ }^{3}$ School of Medicine and Health Management, Tongji Medical College, Huazhong University of Science and Technology, Wuhan, China

${ }^{4}$ Centre for the Health Economy, Macquarie University, Sydney, New South Wales, Australia

Correspondence to Professor Dongfu Qian; dongfu016@126.com

\section{ABSTRACT}

Objectives Government healthcare subsidies for healthcare facilities play a significant role in providing more extensive healthcare access to patients, especially poor ones. However, equitable distribution of these subsidies continues to pose a challenge in rural ethnic minority areas of China. This study aimed to evaluate the benefits distribution of outpatient services across different socioeconomic populations in China's rural ethnic minority areas.

Setting Inner Mongolia Autonomous Region, Xinjiang Autonomous Region and Qinghai Province.

Design Two rounds of cross-sectional study.

Participants One thousand and seventy patients in 2010 and 907 patients in 2013, who sought outpatient services prior to completing the household surveys, were interviewed.

Methods Benefits incidence analysis was performed to measure the benefits distribution of government healthcare subsidies across socioeconomic groups. The concentration index (Cl) for outpatient care at different healthcare facility levels in rural ethnic minority areas was calculated. Two rounds of household surveys using multistage stratified samples were conducted.

Findings The overall $\mathrm{Cl}$ for outpatient care was -0.0146 $(P>0.05)$ in 2010 and $-0.0992(P<0.01)$ in 2013. In 2010 , the $\mathrm{Cl}$ was $-0.0537(\mathrm{P}<0.01),-0.0085(\mathrm{P}>0.05)$ and $-0.0034(P>0.05)$ at levels of village clinics (VCs), township health centres (THCs) and county hospitals (CHs), respectively. In 2013, the $\mathrm{Cl}$ was $-0.1353(\mathrm{P}<0.05)$, $-0.0695(P>0.05)$ and $-0.1633(P<0.01)$ at the levels of VCs, THCs and $\mathrm{CHs}$, respectively.

Conclusion Implementation of the gatekeeper mechanism helped improve the benefits distribution of government healthcare subsidies in rural Chinese ethnic minority areas. Equitable distribution of government healthcare subsidies for VCs was improved by increasing financial input and ensuring the performance of primary healthcare facilities. Equitable distribution of subsidies for CHs was improved by policies that rationally guided patients' care-seeking behaviour. In addition, highly qualified physicians were also a key factor in ensuring equitable benefits distribution.
Strengths and limitations of this study

- This study was the first to evaluate the equity of government healthcare subsidy in China's rural ethnic minority areas.

- Data collection on unit subsidies for outpatient care was not based on each healthcare facility level, but rather on each individual facility. The interviewed patients were required to provide proof of outpatient visits for the previous 2 weeks and the name(s) of the healthcare facility/facilities they used.

- It should be acknowledged that our study was limited to the use of self-reported household expenditures to classify living standards. Although expenditures are recognised as the preferred measure of living standards, self-reported household expenditures might be inaccurate due to recall bias.

- Despite respondent and survey method homogeneity between the two rounds of investigation, the crosssectional study design could not allow a strong conclusion to be reached.

\section{INTRODUCTION}

Ensuring equity in government healthcare subsidy distribution is a growing priority for low-income and middle-income countries. ${ }^{1-3}$ Increasingly, in China, the rising cost of healthcare and direct payment mechanisms have led to a continuous increase in healthcare prices. ${ }^{45}$ Thus, government healthcare subsidies play a significant role in reducing healthcare prices and providing more extensive healthcare access for patients, especially those in lower socioeconomic groups. The subsidies have improved healthcare service usage by different socioeconomic groups. These healthcare services are provided by different types of hospitals, including primary-level clinics and district, regional and central hospitals. ${ }^{6}$ Specifically, China's healthcare bureau worked in conjunction with the price bureau to formulate appropriate healthcare prices in hospitals that 
are affordable to local residents while the deficit between healthcare prices and hospital costs is compensated by government healthcare subsidies. In other words, patients who consume medical services will receive the subsidies. ${ }^{78}$

However, there is an increasing concern that rich patients might be the principal beneficiaries because they have a higher ability-to-pay (ATP) for medical care and consequently have more opportunity to receive subsidies. ${ }^{9-11}$ Although there have been many benefit incidence analyses (BIAs) carried out in developed and urban areas in China, ${ }^{7812} 13$ far too little attention has been paid to rural Western China. Healthcare usage in Western China, the area in which most of the ethnic minority populations reside, is a priority for China's fiscal redistribution policies. However, the distribution of government healthcare subsidies across different income groups in rural ethnic minority areas of China remains unknown. Limited healthcare and human resources, low literacy levels, lack of basic health knowledge, underdeveloped socioeconomic conditions, unhealthy diet and lifestyle, poor transportation and cultural differences may impede the equitable distribution of government healthcare subsidies. $^{14-16}$

Taking outpatient care as an example, this could be provided by a village clinic (VC), township health centre (THC) or county hospital $(\mathrm{CH})$. On the provider side, VCs and THCs are the primary healthcare providers in rural ethnic minority areas; these facilities are short of qualified healthcare personnel, medical equipment, medicines and technical support, and they tend to have delayed or missing government healthcare subsidies, leading to insufficient outpatient services for local residents. ${ }^{17} 18$ On the demand side, patients often believe that a high-level healthcare facility (such as a $\mathrm{CH}$ ) has better medical technology than a grass-roots hospital. As a result, patients tend to seek medical care directly at $\mathrm{CHs}$. However, the prices of medical service offered by $\mathrm{CHs}$ are higher than those offered by VCs and THCs. The affluent population was the major group who could afford to seek medical services in these medical institutions, while many poor individuals had to abandon medical treatment as a result of poor public transportation and poor roads. ${ }^{19} 20$ Consequently, these poorer patients failed to benefit from government healthcare subsidies, which contributed to a distribution of these subsidies that was not pro-poor in rural ethnic minority areas of China.

Confronted with such a situation, local government has made growing efforts since 2011 to improve the equitable distribution of government healthcare subsidies. In addition, in 2011, a hierarchical medical system was established in the Inner Mongolia Autonomous Region, Xinjiang Autonomous Region and Qinghai Province, areas in which the greatest majority of China's ethnic minorities live. Hierarchical medical care packages have included increasing financial subsidies and upgrades in the medical service quality of primary healthcare providers in addition to improvements in the medical technology available to healthcare staff.
At the same time, the gatekeeper mechanism was implemented and patients were required to choose VCs as their first-visit facility. Because China had not previously implemented a gatekeeper mechanism, patients could previously have chosen any level of medical institution as their first-visit facility. This type of care-seeking behaviour led to inefficient use of health resources and rising medical expenditures. To alter this phenomenon, local healthcare bureaus required patients to first seek medical treatment in primary-level healthcare facilities. If referral was necessary after diagnosis, a certificate of referral would be signed, sealed and provided by the village doctor as a voucher for patients to be referred to a THC or CH. These measures increased the outpatient visit rate to VCs to a large extent, but there was no evidence to demonstrate a variation in the distribution of government healthcare subsidies following the implementation of these new policies.

Therefore, in our study, two rounds of cross-sectional survey were conducted in the pilot areas before and after the implementation of the hierarchical medical system. This paper analyses the outpatient service benefits distribution at different healthcare facility levels in rural ethnic minority areas of China in order to explore the equity of government healthcare subsidy distribution. This will be of great significance for restructuring and improving the healthcare system in these areas and for improving the equity associated with government healthcare subsidies.

\section{METHODS \\ Ethnic minority areas assessed}

In our study, two rounds of household surveys were carried out in the Inner Mongolia Autonomous Region, Xinjiang Autonomous Region, and Qinghai Province, which are the major areas for China's minority nationalities. The two rounds were conducted in 2011 and 2014 to record information for 2010 and 2013, respectively. The Inner Mongolia Autonomous Region, located in the north of the county, spans approximately 1.2 million $\mathrm{km}^{2}$ or $12.3 \%$ of China's total land area. The various ethnic groups living there comprise approximately $20.5 \%$ of the population of Inner Mongolia. Xinjiang Autonomous Region, located in the north-west of the country, spans an area of 1.6 million $\mathrm{km}^{2}$ and is the largest administrative division in China, constituting about $16.67 \%$ of the total land area. The various ethnic groups living there comprise approximately $59.4 \%$ of the population of Xinjiang. Qinghai Province, located in the north-west of the country, is the fourth largest province in China, spanning an area of 0.72 million $\mathrm{km}^{2}$. The various ethnic groups in that area comprise about $47.0 \%$ of the population of Qinghai. ${ }^{21}$

\section{Household surveys}

Multistage stratified random sampling was used for the household surveys. In both Xinjiang and the Inner Mongolia Autonomous Region, counties with higher and 
Table 1 Descriptive statistics and socioeconomic characteristics of the sample by income quintile

\begin{tabular}{|c|c|c|c|c|c|c|c|c|}
\hline \multirow[b]{2}{*}{ Year } & \multirow[b]{2}{*}{$\begin{array}{l}\text { Income } \\
\text { quintile }\end{array}$} & \multirow[b]{2}{*}{$\begin{array}{l}\text { Number of } \\
\text { respondents }\end{array}$} & \multirow[b]{2}{*}{$\begin{array}{l}\text { Per capita household } \\
\text { expenditure }{ }^{\star}(95 \% \mathrm{Cl}) \dagger\end{array}$} & \multirow[b]{2}{*}{ Outpatient subsidy } & \multicolumn{4}{|c|}{ Sought medical care } \\
\hline & & & & & $\begin{array}{l}\text { Village } \\
\text { clinic (\%) }\end{array}$ & $\begin{array}{l}\text { Township } \\
\text { health centre } \\
\text { (\%) }\end{array}$ & $\begin{array}{l}\text { County hospital } \\
\text { (\%) }\end{array}$ & Total (\%) \\
\hline \multirow{3}{*}{2010} & 2 & 212 & $1797.30(1706.65$ to 1887.95$)$ & 545.52 (463.58 to 627.46$)$ & 47.83 & 27.83 & 24.35 & 100 \\
\hline & 3 & 223 & 3078.00 (2899.56 to 3256.44$)$ & 658.43 (573.70 to 743.17 ) & 40.16 & 23.77 & 36.07 & 100 \\
\hline & Total & 1070 & 3808.46 (3558.59 to 4058.33$)$ & 570.57 (535.14 to 606.00$)$ & 45.50 & 26.28 & 28.22 & 100 \\
\hline \multirow[t]{4}{*}{2013} & 1 -poorest & 175 & 578.21 (525.78 to 630.64$)$ & $1610.08(1049.05$ to 2171.11$)$ & 76.92 & 15.98 & 7.10 & 100 \\
\hline & 2 & 187 & 1486.15 (1381.76 to 1590.55$)$ & 1192.03 (927.12 to 1456.94$)$ & 67.96 & 20.44 & 11.60 & 100 \\
\hline & 3 & 184 & 2514.07 (2315.42 to 2712.73$)$ & $1204.29(880.07$ to 1528.51$)$ & 67.80 & 19.21 & 12.99 & 100 \\
\hline & 4 & 174 & 3524.20 (3275.90 to 3772.50$)$ & 907.43 (672.12 to 1142.73$)$ & 80.24 & 11.38 & 8.38 & 100 \\
\hline
\end{tabular}

Data source: author's calculations from household survey.

*All expenditures and outpatient subsidies are presented in 2013's real prices in Chinese Yuan (¥).

†95\% Cls are reported in parentheses.

lower per-capita gross domestic product were sampled. Qinghai Province has traditionally been divided into farming and pasturing areas. Thus, two counties were selected, one from each of these two areas. In total, eight counties were sampled in our study. Four towns were sampled from each county according to their geographical distribution, and three villages were then randomly selected from each town. In each village, trained data collectors went to households and checked the medical bills and/or insurance records of the household members in order to identify whether the patients sought outpatient services prior to the household surveys. Approximately 10 residents per village were selected for this study. Finally, 1070 outpatients in 2010 and 907 outpatients in 2013 were enrolled and surveyed (table 1).

Each interview comprised a series of questions about socioeconomics and demographics, including number, age, gender, education and employment status of household members in addition to questions about household expenditures and goods. Information on monthly household expenditures for food, housing, clothing, traffic, electricity, water, fuel, communication, education, exercise, entertainment, medical care and other types of expenditures was collected from the household head or the family member most familiar with the household's affairs. Unexpected expenditures during the previous year were also recorded. According to the patient's medical bills or insurance records, healthcare usage and the name of the healthcare facility used for outpatient visits were also recorded. Living standards were estimated from household expenditure per equivalent adult. ${ }^{22}$

\section{Healthcare facilities survey}

A survey of healthcare facilities was also conducted in the regions investigated. All facilities that provided outpatient services, including VCs, THCs and CHs, were surveyed.
Information on the facility name, government subsidies, outpatient visits, inpatient days and outpatient and inpatient expenditures at each facility in 2010 and 2013 was collected from an examination of hospital financial records.

The data used to assess per-capita government subsidies on outpatient care were collected from two sources. One source was the facilities survey described above while the other was the household surveys, each of which involved recording information from the interviewed outpatients on healthcare usage (such as outpatient visits for the previous 2 weeks and the name of the visited healthcare facility). According to the facility name, outpatient visits by the patients were matched to the healthcare provision by the healthcare facilities in which the patients received outpatient services.

\section{Data analysis}

Calculation of unit subsidies

Data pertaining to government subsidies, outpatient and inpatient expenditures, outpatient visits and inpatient days at each facility were obtained from each healthcare facilities survey. However, it was not possible to obtain information on separate government subsidies for outpatient and inpatient services. Because patients received government subsidies only if they used healthcare in hospitals, the assumption was made that the proportion of subsidies allocated between outpatient and inpatient care was equal to the ratio of outpatient to inpatient expenditure. ${ }^{78}$ The facility-specific unit subsidy for outpatient care was then calculated by dividing the total amount of outpatient subsidies by the total number of outpatient visits at each healthcare facility. The subsidy for each outpatient was the total outpatient usage multiplied by the unit subsidy at each facility. 


\section{Benefit incidence analysis}

BIA was employed in this study to estimate the distribution of government subsidies across individuals ranked according to their living standards. ${ }^{23}$ To evaluate whether government subsidies for outpatient care are progressive or whether poorer patients receive a larger share of subsidies than better-off patients, BIA uses the concentration index (CI) to measure the degree of equity.

Estimates of the CI can be obtained from ordinary least squares (OLS) regression of ATP variables and government outpatient subsidies on the fractional rank according to the ATP distribution. ${ }^{24}$ The value of household expenditures was used as a measure of ATP. Adjustment was made for the size and age structure of each household by applying an adult equivalence $(A E)$ scale to the measure of ATP. The scale used was:

$$
A E=(A+0.5 K)^{0.75}
$$

where $A$ is the number of adults in the household and $K$ is the number of children ( $0-14$ years).$^{22}$ Estimates of the CI can then be obtained from OLS regression:

$$
2 \sigma^{2}\left(\frac{Z_{i}}{\gamma}\right)=\alpha+\beta X_{i}+\varepsilon
$$

where $Z_{i}$ is the government healthcare subsidy to individual $i, \gamma$ is an estimate of the mean government healthcare subsidy, $X_{i}$ is the household fractional rank according to the ATP distribution and $\sigma^{2}$ is its variance. The OLS estimate of $\beta$ is an estimate of the CI. ${ }^{23}$

\section{Dominance test}

In addition, a dominance test was added to the BIA. To establish whether healthcare subsidies reduced inequity in the sense that lower-income individuals receive a larger share of the subsidies than the wealthy, compared with their living standards, a test of whether the concentration curve dominates (lies above) the Lorenz curve of household expenditure was conducted. A multiple comparison approach to testing was adopted, with the null defined as indistinguishable curves. ${ }^{23}$

\section{RESULTS}

The income quintile shares and CI of government subsidies for outpatient care at different healthcare facility levels in rural ethnic minority areas are shown in tables 2 and 3.

In 2010, at all levels of healthcare facility, the only CI with a statistically significantly negative value was found to be that for outpatient services at VCs (-0.0537), indicating that poorer patients received a greater proportion of government healthcare subsidies than better-off patients when they sought outpatient care at VCs. The CI values for THCs $(-0.0085)$ and CHs (-0.0034), although negative, were not significantly different from zero, implying that government healthcare subsidies for those facilities were not pro-poor. Generally, with regard to the subsidies across all levels of healthcare facilities, the CI value was found to be negative but not statistically significant $(-0.0146)$, indicating that government healthcare subsidies were not pro-poor in 2010 in the rural Chinese ethnic minority regions. Figure 1 , showing the plots of Lorenz and concentration curves, provides a visual

Table 2 Distribution of government healthcare subsidies by income quintile, Gini/concentration index (Cl) and Kakwani

\begin{tabular}{|c|c|c|c|c|c|}
\hline Income quintile & $\begin{array}{l}\text { Per capita } \\
\text { household } \\
\text { expenditure }\end{array}$ & Total & Village clinic & $\begin{array}{l}\text { Township health } \\
\text { centre }\end{array}$ & County hospital \\
\hline 1 -poorest & $4.11 \%$ & $20.48 \%$ & $24.78 \%$ & $26.00 \%$ & $12.57 \%$ \\
\hline 2 & $9.38 \%$ & $18.87 \%$ & $19.93 \%$ & $19.45 \%$ & $17.14 \%$ \\
\hline 3 & $17.05 \%$ & $24.07 \%$ & $21.57 \%$ & $21.44 \%$ & $28.49 \%$ \\
\hline 4 & $23.13 \%$ & $18.19 \%$ & $17.32 \%$ & $11.89 \%$ & $21.10 \%$ \\
\hline Gini/Cl & $0.4293^{\star *}$ & -0.0146 & $-0.0537^{\star \star}$ & -0.0085 & -0.0034 \\
\hline $95 \% \mathrm{Cl}$ & (0.4020 to 0.4566$) \dagger$ & $(-0.0503$ to 0.0212$)$ & $(-0.0918$ to -0.0157$)$ & $(-0.0883$ to 0.0713$)$ & $(-0.0221$ to 0.0153$)$ \\
\hline $\mathrm{KI}$ & - & $-0.4469^{\star \star}$ & $-0.5110^{\star \star}$ & $-0.5731^{\star *}$ & $-0.3076^{\star \star}$ \\
\hline $95 \% \mathrm{Cl}$ & - & $(-0.4952$ to -0.3986$)$ & $(-0.5644$ to -0.4576$)$ & $(-0.6985$ to -0.4477$)$ & $(-0.3600$ to -0.2551$)$ \\
\hline $\begin{array}{l}\text { Against Lorenz } \\
\text { curve }\end{array}$ & - & $\mathrm{D}+$ & $\mathrm{D}+$ & $\mathrm{D}+$ & $\mathrm{D}+$ \\
\hline
\end{tabular}
Index (KI) in 2010

$\mathrm{D}+/ \mathrm{D}-$ indicates that the concentration curve dominates/is dominated by the Lorenz curve.

${ }^{*} \mathrm{P}<0.05 ;{ }^{* \star} \mathrm{P}<0.01$.

†95\% Cls are reported in parentheses. 
Table 3 Distribution of government healthcare subsidies by income quintile, Gini/concentration index (Cl) and Kakwani Index (KI) in 2013

\begin{tabular}{|c|c|c|c|c|c|}
\hline Income quintile & $\begin{array}{l}\text { Per capita } \\
\text { household } \\
\text { expenditure }\end{array}$ & Total & Village clinic & $\begin{array}{l}\text { Township health } \\
\text { centre }\end{array}$ & County hospital \\
\hline 1-poorest & $3.52 \%$ & $26.33 \%$ & $32.21 \%$ & $25.52 \%$ & $20.56 \%$ \\
\hline 2 & $9.38 \%$ & $20.77 \%$ & $18.30 \%$ & $21.23 \%$ & $22.74 \%$ \\
\hline 3 & $15.86 \%$ & $20.67 \%$ & $14.64 \%$ & $21.13 \%$ & $26.44 \%$ \\
\hline 4 & $20.77 \%$ & $14.70 \%$ & $21.75 \%$ & $12.60 \%$ & $10.79 \%$ \\
\hline Gini/Cl & $0.4535^{\star \star}$ & $-0.0992^{\star \star}$ & $-0.1353^{\star}$ & -0.0695 & $-0.1633^{\star \star}$ \\
\hline $95 \% \mathrm{Cl}$ & $(0.4235$ to 0.4834$) \dagger$ & $(-0.1725$ to -0.0259$)$ & $(-0.2539$ to -0.0166$)$ & $(-0.1618$ to 0.0227$)$ & $(-0.2855$ to -0.0410$)$ \\
\hline $\mathrm{KI}$ & - & $-0.5547^{\star *}$ & $-0.5885^{\star \star}$ & $-0.5642^{* \star}$ & $-0.5310^{\star *}$ \\
\hline $95 \% \mathrm{Cl}$ & - & $(-0.6342$ to -0.4752$)$ & $(-0.7143$ to -0.4626$)$ & $(-0.6791$ to -0.4492$)$ & $(-0.6544$ to -0.4076$)$ \\
\hline $\begin{array}{l}\text { Against Lorenz } \\
\text { curve }\end{array}$ & - & $\mathrm{D}+$ & $\mathrm{D}+$ & $\mathrm{D}+$ & D+ \\
\hline
\end{tabular}

D+/D- indicates that the concentration curve dominates/is dominated by the Lorenz curve. 'None' indicates failure to reject the null hypothesis that the curves are indistinguishable at the $5 \%$ significance level.

${ }^{*} \mathrm{P}<0.05$; ${ }^{\star *} \mathrm{P}<0.01$.

†95\% Cls are reported in parentheses.

sense of the progressivity of government healthcare subsidies at each level of rural healthcare facility and the total subsidies in 2010.

In 2013, we found that the CI values were statistically significantly negative for both VCs $(-0.1353)$ and CHs $(-0.1633)$, suggesting that a greater proportion of government healthcare subsidies were allocated to the poor in those facilities. On the other hand, the CI value for THCs was negative $(-0.0695)$ but not statistically significantly, indicating that government healthcare subsidies were not pro-poor in those facilities. Generally, with regard to subsidies across all levels of healthcare facility, the CI value was found to be statistically significantly negative $(-0.0992)$, indicating that government healthcare subsidies for outpatient care showed a pro-poor bias. Figure 2, showing plots of Lorenz and concentration curves, provides a visual sense of the progressivity of government healthcare subsidies at each level of rural healthcare facility and the total subsidies in 2013.

Comparing data from 2013 with those from 2010, a much greater proportion of government healthcare subsidies were allocated to the poor in 2013 than in 2010, as evidenced by the decreased CI. At each level of healthcare facility, government healthcare subsidies for VCs were pro-poor in both years and the CI was decreased over the period 2010-2013. The subsidies for THCs were not pro-poor in either year. With regard to $\mathrm{CHs}$, subsidies were not pro-poor in 2010 but became pro-poor in 2013 .

\section{DISCUSSION}

Generally, the benefits distribution of government healthcare subsidies for outpatient care was proportional in 2010 in rural ethnic minority areas and became fairly even by 2013. In 2010, VCs were the only providers with a benefits distribution that favoured the poor. This result is consistent with results from other developing countries. ${ }^{25-28}$ Government healthcare subsidies for THCs and CHs were proportional. The decrease in the CI in 2013 is evidence that the equitable distribution of government healthcare subsidies for VCs further improved. On the other hand, the distribution of government healthcare subsidies for CHs changed from proportional to pro-poor. In contrast, the outpatient benefits distribution for THCs remained proportional.

This trend is largely attributable to the implementation of hierarchical medical systems in China's ethnic areas. To effectively establish a hierarchical medical system and ensure equitable, affordable and high-quality medical services for patients using primary healthcare providers, local health departments have also formulated and implemented corresponding supportive policy packages. Local health bureaus have increased subsidies for VCs and improved standardised VC construction. Each standardised VC has been allotted one general practitioner and two public health physicians, who are required to be qualified as licensed doctors or licensed assistant doctors. Each VC is required to be equipped with separate outpatient, treatment, injection and transfusion rooms and a pharmacy, in addition to any necessary medical equipment. Village doctors' professional qualifications are strictly regulated. Village doctors should meet the qualification standards required by the Law for Licensing Medical Practitioners' or Rural Doctors' Working Regulations. Doctors who receive formal general practice 

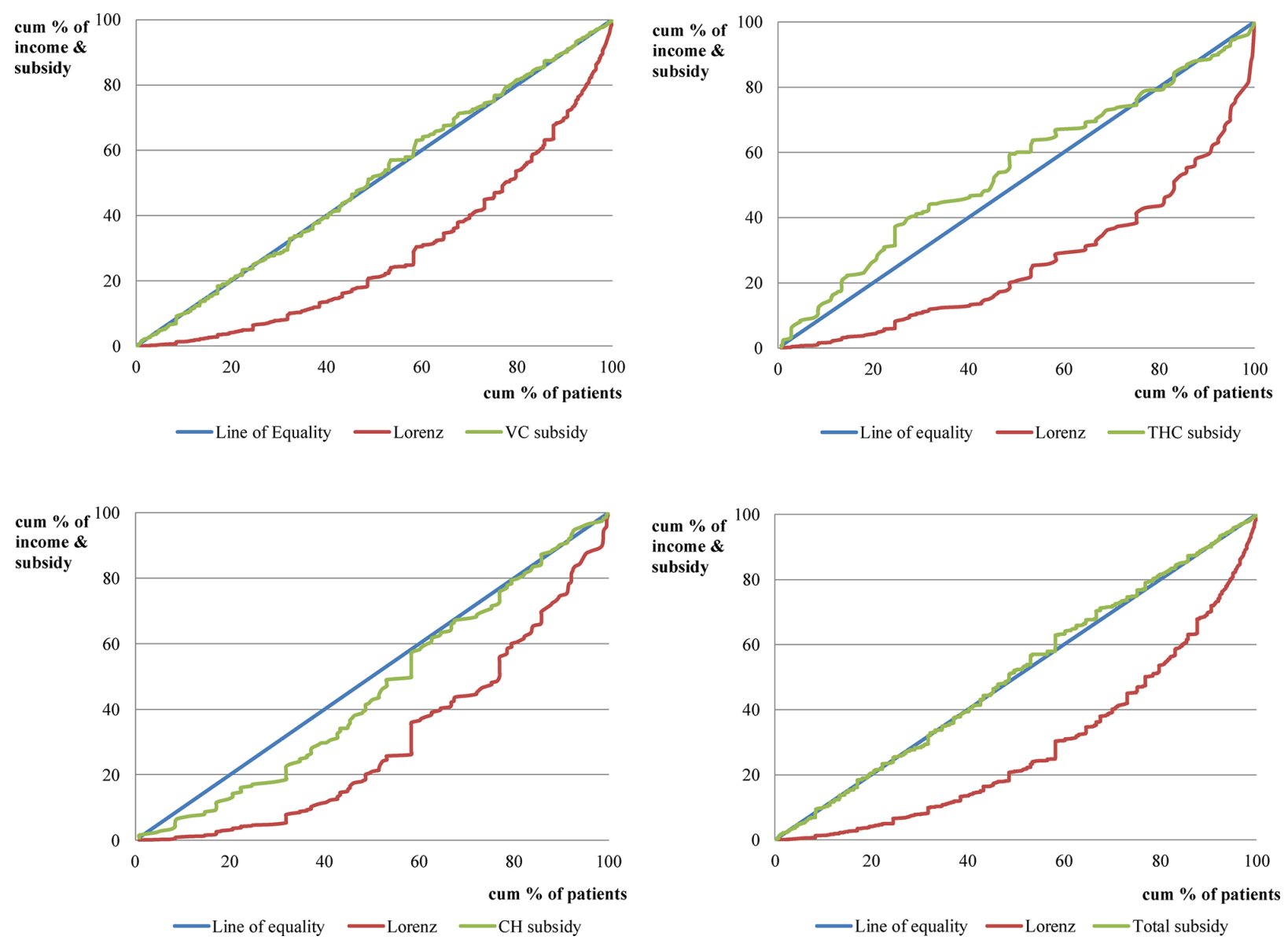

Figure 1 Concentration curves of government healthcare subsidies at different healthcare facility levels in 2010. Lorenz curves and cumulative concentration curves for government outpatient subsidies in China's rural ethnic minority areas for 2010 data at different healthcare facility levels (VC, THC and $\mathrm{CH}$ ) are shown. $\mathrm{CH}$, county hospital; THC, township health centre; VC, village clinic.

training and pass the corresponding examination set-up by the provincial health department are considered qualified village doctors. Healthcare professionals practising medicine, nursing or public health should be registered at local health administrative departments and operate within the required scope of practice.

On the other hand, care-seeking behaviour is rationally guided by the reimbursement policy of the rural health insurance scheme, the New Rural Cooperative Medical System. Patients seeking healthcare at VCs are compensated with the highest medical expenditure reimbursement rate, while the rate is lower for patients who seek care at THCs and CHs. In addition, medicines provided at VCs are all covered by the health insurance reimbursement scheme. What is more, VCs are managed according to China's Essential Medicine Policy and Zero-Markup Policy. VCs should prescribe essential medicines for common, frequent and endemic diseases. At the same time, the Zero-Markup Policy has been implemented in order to abolish medicine mark-up.

Moreover, VCs are compensated by the county health bureau based on their number of patient visits. Taking the Inner Mongolia Autonomous Region as an example, a VC could be compensated 3.5 renminbi (RMB) for each patient visit, of which 2.5 RMB is approved and appropriated on a monthly basis, and the remaining 1.0 RMB is supplied at county level to reward VCs with superior performance. The performance assessment is based on the provision of patient incentives for seeking village doctors, improvements in service quality, and reductions in medical expenditures. Allocation of government healthcare subsidies is based on each VC's performance assessment ranking. VCs that are ranked higher are allocated additional subsidies while those ranked lower are allocated deductible subsidies.

Owing to implementation of the gatekeeper mechanism, many more rural residents have sought medical treatment at VCs, especially residents in low-income groups, who benefit from the enhanced medical quality of VCs and the upgraded medical technology available to village doctors. Patients' economic burdens have been reduced because of the reimbursement policy of the rural health insurance scheme (the Zero-Markup Policy) and savings in transport costs. This has led to the lower socioeconomic groups receiving much more government healthcare subsidies at the VC level, thus improving the equity of the benefits distribution. 

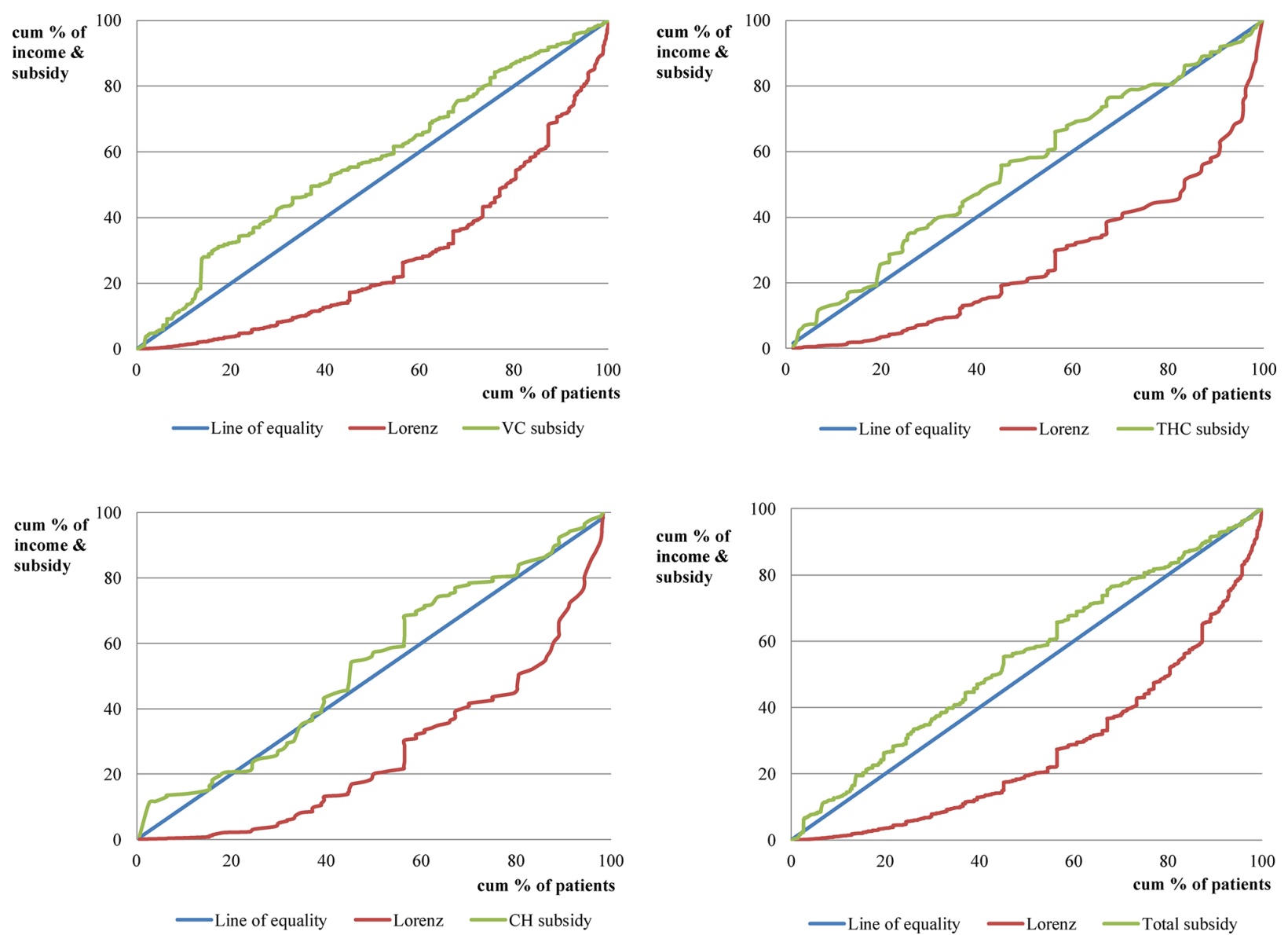

Figure 2 Concentration curves of government healthcare subsidies at different healthcare facility levels in 2013 . Lorenz curves and cumulative concentration curves for government outpatient subsidies in China's rural ethnic minority areas for 2013 data at different healthcare facility levels (VC, THC and $\mathrm{CH}$ ) are shown. $\mathrm{CH}$, county hospital; THC, township health centre; VC, village clinic.

In addition, it has been found that the equity of distribution of government healthcare subsidies for $\mathrm{CHs}$ changed from proportional to pro-poor. After implementation of the gatekeeper mechanism, care-seeking behaviours at CHs has been based on patients' health status and healthcare demands, instead of their ATP. Because poorer patients tend to have a greater need for healthcare compared with better-off patients, ${ }^{29}{ }^{30}$ healthcare usage by the former has been greater than that by the latter, and the benefits distribution of government healthcare subsidies for CHs has improved. ${ }^{631}$

In contrast, the equity of distribution of government healthcare subsidies for THCs remained proportional over the period 2010-2013. In the field investigation, it was found that local government increased financial input into THCs for infrastructure construction and the purchase of medical equipment. However, the qualification requirements for doctors working in THCs have been more extensive than those for VCs, which has resulted in a lack of doctors in THCs. Therefore, the healthcare needs of rural residents are difficult to meet at THCs, and there are fewer patients seeking medical care at THCs. This implies that the skill level of healthcare professionals at THCs needs to be improved by allocating highly educated medical graduates to THCs and strengthening on-the-job training. In this way, the ability to supply highly trained doctors can be improved and the service levels of THCs can be upgraded so that poorer patients can benefit significantly from government healthcare subsidies.

The findings of this study may provide evidence on the effects of the establishment of the hospital referral policy and gatekeeper mechanism, especially the effects of government subsidies at different healthcare facility levels. However, our study was conducted in rural ethnic minority areas in China so we should acknowledge that the local health profile, geographical access to healthcare facilities, healthcare policy priorities and socioeconomic distribution may limit the generalisability of the results.

Although two rounds of cross-sectional surveys were conducted and we found a change in the distribution of government healthcare subsidies for outpatient care in China's rural ethnic minority areas, the cross-sectional nature of the study meant that a strong causal relationship could not be proved. Despite this shortcoming, this study represents an excellent opportunity to analyse changes in the equity of government healthcare subsidies, as the sampled areas, survey methods, and questionnaires were the same, and the investigated healthcare facilities and patients were homogenous in both surveys. 
A limitation of the data collection process was the use of self-reported household expenditures to classify living standards. Despite the fact that expenditures are recognised as a preferred measurement of living standards, self-reported household expenditures might be inaccurate due to recall bias.

\section{CONCLUSIONS}

The benefits distribution of government healthcare subsidies in rural ethnic minority areas of China tended to be equitable. Increased subsidies and improvements to the performance of primary healthcare facilities have contributed to equitable distribution of government healthcare subsidies at the VC level. The gatekeeper mechanism and polices that rationally guide care-seeking behaviour have helped to improve the equity of distribution at the $\mathrm{CH}$ level. In addition, highly qualified physicians are a key factor in ensuring that government healthcare subsidies can be effectively allocated to patients in need.

Acknowledgements We acknowledge the partnership between the China Medical Board office and the study province's local health bureau, which helped organise the field data collection.

Contributors DQ led the study, data analysis and interpretation. MC wrote the manuscript and contributed to the study design. ZF analysed the data and helped in the writing of the final draft of the manuscript. LS supervised the study, contributed to the study design and wrote the manuscript. All authors read and approved the final manuscript.

Funding This study was funded by the National Natural Science Foundation of China (grant number: 71503137) and the China Medical Board (grant number: 10-030).

Disclaimer The funding bodies were not involved in the design of the study, data collection, analysis, and interpretation, or writing the manuscript.

Competing interests None declared.

Patient consent Obtained.

Ethics approval This study was approved by the Academic Research Ethics Committee of Nanjing Medical University. All procedures were in accordance with the ethical standards of the Helsinki Declaration.

Provenance and peer review Not commissioned; externally peer reviewed.

Data sharing statement The datasets used in this study are not publicly available due to a confidentiality policy, but they are available from the corresponding author on reasonable request.

Open Access This is an Open Access article distributed in accordance with the Creative Commons Attribution Non Commercial (CC BY-NC 4.0) license, which permits others to distribute, remix, adapt, build upon this work non-commercially, and license their derivative works on different terms, provided the original work is properly cited and the use is non-commercial. See: http://creativecommons.org/ licenses/by-nc/4.0/

(c) Article author(s) (or their employer(s) unless otherwise stated in the text of the article) 2018. All rights reserved. No commercial use is permitted unless otherwise expressly granted.

\section{REFERENCES}

1. Mills A, Ataguba JE, Akazili J, et al. Equity in financing and use of health care in Ghana, South Africa, and Tanzania: implications for paths to universal coverage. Lancet 2012;380:126-33.

2. Anselmi L, Lagarde M, Hanson K. Equity in the allocation of public sector financial resources in low- and middle-income countries: a systematic literature review. Health Policy Plan 2015;30:528-45.

3. World Bank. Engendering development: through gender equality in rights, resources, and voice. Washington, DC: World Bank, 2001.
4. Li Y, Wu Q, Xu L, et al. Factors affecting catastrophic health expenditure and impoverishment from medical expenses in China: policy implications of universal health insurance. Bull World Health Organ 2012;90:664-71.

5. Yang T, Chu J, Zhou C, et al. Catastrophic health expenditure: a comparative analysis of empty-nest and non-empty-nest households with seniors in Shandong, China. BMJ Open 2016;6:e10992.

6. Mclntyre D, Ataguba JE. How to do (or not to do)... a benefit incidence analysis. Health Policy Plan 2011;26:174-82.

7. Chen M, Fang G, Wang L, et al. Who benefits from government healthcare subsidies? An assessment of the equity of healthcare benefits distribution in China. PLoS One 2015;10:e119840.

8. Si L, Chen M, Palmer AJ. Has equity in government subsidy on healthcare improved in China? Evidence from the China's national health services survey. Int J Equity Health 2017;16.

9. Gao J, Qian J, Tang S, et al. Health equity in transition from planned to market economy in China. Health Policy Plan 2002;17(Suppl):20-9.

10. Pan J, Tian S, Zhou Q, et al. Benefit distribution of social health insurance: evidence from chinas urban resident basic medical insurance. Health Policy Plan 2016;31:853-9.

11. Huang N, Yip W, Chou YJ, et al. The distribution of net benefits under the National Health Insurance programme in Taiwan. Health Policy Plan 2007;22:49-59.

12. Chen M, Palmer AJ, Si L. Assessing equity in benefit distribution of government health subsidy in 2012 across East China: benefit incidence analysis. Int J Equity Health 2016;15:15.

13. Wang L, Wang A, FitzGerald G, et al. Who benefited from the New Rural Cooperative Medical System in China? A case study on Anhui Province. BMC Health Serv Res 2016;16:195.

14. Harris A, Zhou Y, Liao H, et al. Challenges to maternal health care utilization among ethnic minority women in a resource-poor region of Sichuan Province, China. Health Policy Plan 2010;25:311-8.

15. Li Y, Aranda MP, Chi I, Yawen L, Iris C. Health and life satisfaction of ethnic minority older adults in mainland China: effects of financial strain. Int J Aging Hum Dev 2007;64:361-79.

16. He J, Guo S, Liu J, et al. Ethnic differences in prevalence of general obesity and abdominal obesity among low-income rural Kazakh and Uyghur adults in far western China and implications in preventive public health. PLoS One 2014;9:e106723.

17. Li H, Chi I, Xu L. Life satisfaction of older Chinese adults living in rural communities. J Cross Cult Gerontol 2013;28:153-65.

18. Luo D, Hu J. Factors influencing health-related quality of life among minority elders in southwest China. $J$ Community Health Nurs 2011;28:156-67.

19. O'Donnell O, van Doorslaer E, Rannan-Eliya RP, et al. Who pays for health care in Asia? J Health Econ 2008;27:460-75.

20. Zhou C, Long Q, Chen J, et al. Factors that determine catastrophic expenditure for tuberculosis care: a patient survey in China. Infect Dis Poverty 2016;5.

21. National Bureau Of Statistics of China. http://data.stats.gov.cn/ easyquery.htm?cn=C01 (accessed 30 Jan 2017).

22. Deaton $A$. The analysis of household surveys: a microeconometric approach to development policy. Am J Agr Econ 2000;82:780-2.

23. Donnell OO, van Doorslaer E, Wagstaff A, et al. Analyzing health equity using household survey data: a guide to techniques and their implementation. Washington, DC: World Bank, 2008.

24. Kakwani N, Wagstaff A, van Doorslaer E. Socioeconomic inequalities in health: Measurement, computation, and statistical inference. $J$ Econom 1997;77:87-103.

25. Pannarunothai S, Mills A. The poor pay more: health-related inequality in Thailand. Soc Sci Med 1997;44:1781-90.

26. Gupta S, Verhoeven M, Tiongson ER. Public spending on health care and the poor. Health Econ 2003;12:685-96.

27. Tangcharoensathien V, Limwattananon S, Prakongsai P. Improving health-related information systems to monitor equity in health: lessons from Thailand. Social Science Electronic Publishing 2008;30:222-46.

28. Davoodi HR, Tiongson ER, Asawanuchit SS. Benefit incidence of public education and health spending worldwide: evidence from a new database. Poverty Public Policy 2010;2:191-238.

29. Li YN, Nong DX, Wei B, et al. The impact of predisposing, enabling, and need factors in utilization of health services among rural residents in Guangxi, China. BMC Health Serv Res 2016;16:592.

30. Liu J, Wu J, Mao Y. Research on health services need and utilization of the rural elderly left at home in Shaanxi Province, China. Value Health 2014;17:A797.

31. Wagstaff A. Benefit-incidence analysis: are government health expenditures more pro-rich than we think? Health Econ 2012;21:351-66. 